Fourth International Conference on Sustainable Construction Materials and Technologies http://www.claisse.info/Proceedings.htm

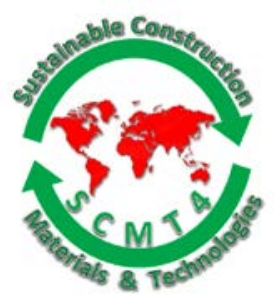

SCMT4

Las Vegas, USA, August 7-11, 2016

\title{
The Experimental Study on the Strength Improvement of Concrete Introducing the Different Electrolyzed Waters
}

\author{
L. Wang ${ }^{1 a}$, K. Uji ${ }^{1 b}$, H. Morozumi ${ }^{2}$, and M.Uemura ${ }^{3}$ \\ ${ }^{1}$ Dept. of Civil and Environmental Engineering, Tokyo Metropolitan University, JAPAN. \\ ${ }^{1 a}$ Email: <shallen12@163.com>, ${ }^{1 b}$ Email: <k.uji@tmu.ac.jp>. \\ ${ }^{2}$ Dept. of Electrolyzed Water Sales, AMANO Maintenance Engineering Co., Ltd, JAPAN. \\ ${ }^{3}$ Representative Director, UEXX Co., Ltd, JAPAN.
}

\begin{abstract}
Nowadays the electrolyzed water has been widely used in industrial and ecological cleaning, food hygiene as well as drinking water industry, but it has not been considered as a method in concrete technology to improve the strength and durability of concrete. In this study, four kinds of different electrolyzed water were used in concrete and the influences on the strength of concrete have also been investigated, including the cathode water (2 types), anode water and slightly alkaline ionized water. The results showed that the strength of cathode electrolyzed water concrete increased by $22 \%$ at $14 \mathrm{~d}$, increased by $12.6 \%$ at $91 \mathrm{~d}$ in comparison to natural water concrete. The strength of slightly alkaline ionized water concrete increased by $9.7 \%$ at $91 \mathrm{~d}$. However, the strength of anode water concrete decreased by $6.4 \%$ at $91 \mathrm{~d}$. In addition, when the PH and ORP (Oxidation-Reduction Potential) value of electrolyzed water were in a certain range, the compressive strength of electrolyzed water concrete increased with $\mathrm{PH}$ value, but decreased with ORP value overall. An adequate $\mathrm{pH}$ value of electrolyzed water should be controlled below 10 that could avoid the damage to the human body and the property of concrete, and an adequate ORP value should be controlled around 200.The results of TG/DTA test for mortar showed the CH amount in cathode electrolyzed water mortar was obviously higher than that in natural water mortar at each age. The generation of more C-S-H gels and reduction of the porosity may be the main reasons for the strength improvement of electrolyzed water concrete. Effective utilization of electrolyzed water in concrete would reduce the cost for cement production and concrete construction, this has good economic benefits and environmental benefits.
\end{abstract}

\section{INTRODUCTION}

Tap water is used as raw material for electrolyzed water, the water is functionalized during the electrolysis process when the electrolyte solution is put into the water-ionizer. It has been widely developed in Europe and the United States, Japan, Korea, Taiwan and Southeast Asia. Currently the electrolyzed water is mainly used on food hygiene (degermation and cleaning of raw material), 
industrial cleaning (rust-proof and cleaning of metal) and environmental cleaning (decontamination ability). Therefore, many researchers focused on the aspects about the sterilization and disinfection of electrolyzed water [Ahmad R 2015] [Mahmoudreza2015] [Tian Ding 2016].etc, but there are few researches about application in concrete industry to improve the properties of concrete. Sun. B.Q researched that the total porosity of concrete mixing alkaline redox potential water decreased by $20 \%$, and the carbonation depth of concrete at $28 \mathrm{~d}$ decreased by $16 \%$ than that of normal concrete. The alkaline redox potential water can improve the durability of concrete [Sun and Wang 2009]. The electrolyte has an effect on the resistivity of ionic conduction concrete [Tan wei 2014] ; the solution composition of water also has an effect on chloride diffusion coefficient in concrete [Song and Jiang]. If electrolyzed water can effectively improve the performance of concrete, this will promote the development of concrete industry in a new field.

The electrolyzed water is a kind of active water, in an electrolyzing cell with diaphragm, due to electrolyte solution of definite concentration of electrolytic treatment (strong alkali $(\mathrm{NaOH} 、 \mathrm{KOH}$ 、 $\left.\mathrm{Ba}(\mathrm{OH})_{2}\right)$, most of the salts ( $\mathrm{NaCl} 、 \mathrm{CaCl}_{2}$.etc) and strong polar compounds ), alkaline electrolyzed water is generated on the cathode, and the acidic electrolyzed water is generated on the anode. Different kinds of electrolyzed water can be obtained from different electrolyte solution. PH value of electrolyzed water can also be adjusted by some devices. Taking the $\mathrm{K}_{2} \mathrm{CO}_{3}$ electrolyte solution as example here, the detailed production princple is shown in Figure.1.

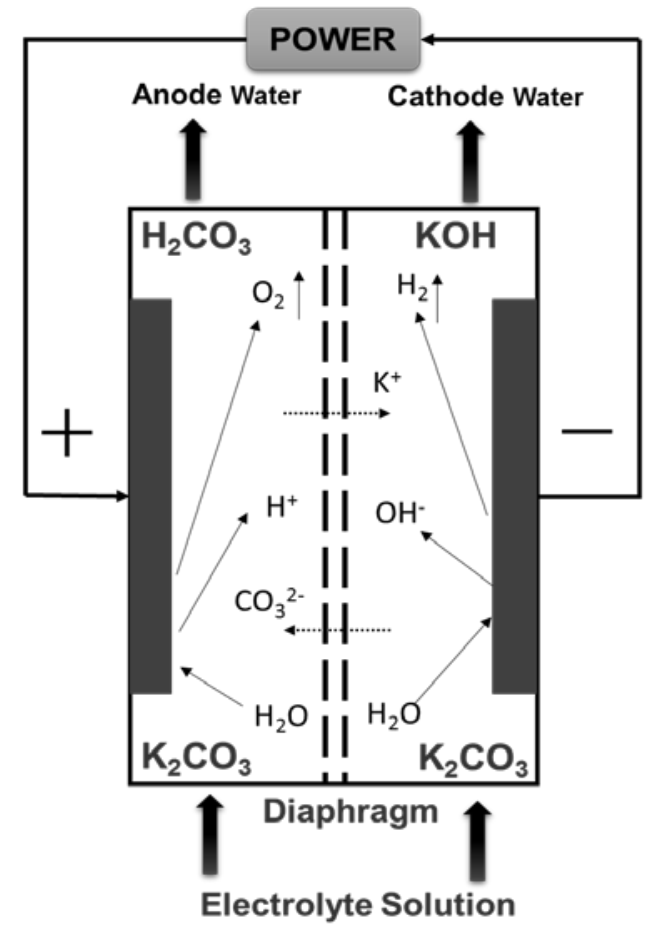

Figure 1. Production principle of electrolyzed water

From the figure 1 ,we can see that through the electrolysis of $\mathrm{K}_{2} \mathrm{CO}_{3}$ electrolyte solution , on the one hand, the reaction on the anode side is :

$2 \mathrm{H}_{2} \mathrm{O} \longrightarrow \mathrm{O}_{2}+4 \mathrm{H}^{+}+4 \mathrm{e}^{-}$

$\mathrm{CO}_{3}{ }^{2-}+2 \mathrm{H}^{+} \longrightarrow \mathrm{H}_{2} \mathrm{CO}_{3}$ 
On the other hand, the reaction on cathode side is:

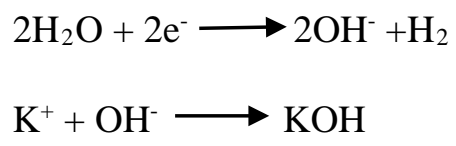

Therefore, $\mathrm{KOH}$ is generated on the cathode, the water is decomposed into hydrogen and hydroxyl ions, it is a slightly alkaline solution; meanwhile, carbonic acid is generated on the anode, the water (H2O) is decomposed into oxygen and hydrogen ions, it is a slightly acid solution.

In this study, many kinds of different electrolyzed water from various aqueous electrolyte solutions were used to produce the concrete. By comparing with the strength of natural water concrete, the influences of different electrolyzed water on the properties of concrete were analyzed and determined. The optimum range for $\mathrm{PH}$ and ORP values of electrolyzed water used for oncrete could be obtained.Through the further study on the $\mathrm{CH}$ content of electrolyzed water mortar by the TG / DTA experiments , the degree of cement hydration and internal reaction mechanism of electrolyzed water used in concrete may be determined eventually.

\section{EXPERIMENTAL INVESTIGATION}

Materials. The Ordinary Portland cement and different kinds of electrolyzed water were used in this study. The cement met the requirements of Japanese Industrial Standard (JIS) R5210. Two kinds of natural river sand (different thickness levels) and crushed quartzite stone were used as fine aggregate and coarse aggregate, respectively. The apparent density, bulk density, water absorption, and fineness modulus of coarse sand and fine sand were $2.63 \mathrm{~g} / \mathrm{cm}^{3}, 1.71 \mathrm{~kg} / \mathrm{l}, 1.40 \%$, and 2.92 and $2.65 \mathrm{~g} / \mathrm{cm}^{3}, 1.52$ $\mathrm{kg} / \mathrm{l}, 2.89 \%$, and 1.58 , respectively. The apparent density, bulk density, water absorption, and fineness modulus of coarse aggregate were $2.62 \mathrm{~g} / \mathrm{cm}^{3}, 1.47 \mathrm{~kg} / \mathrm{l}, 1.90 \%$, and 6.74 . The water reducing admixture (WRA) which was diluted by 4 times and air entraining admixture(AE) which was diluted by 100 times in accordance with Japanese Industrial Standard for Chemical Admixtures for Concrete (JIS) A 6204 were used in this study.

Electrolyzed water. Four kinds of electrolyzed water were obtained from AMANO Maintenance Engineering Co., Ltd in JAPAN, which are the alkaline cathode electrolyzed water $1\left(\mathrm{~K}_{2} \mathrm{CO}_{3}\right.$ electrolyte solution), alkaline cathode electrolyzed water 2 , anode electrolyzed water and slightly alkaline ionized water. The PH and ORP value were different depend on type of electrolyzed water. The PH meter and ORP meter were shown in Figure 2, which were used to test the PH and ORP values of electrolyzed water in this study. In addition, the properties of different electrolyzed water and admixtures were presented in Table 1.
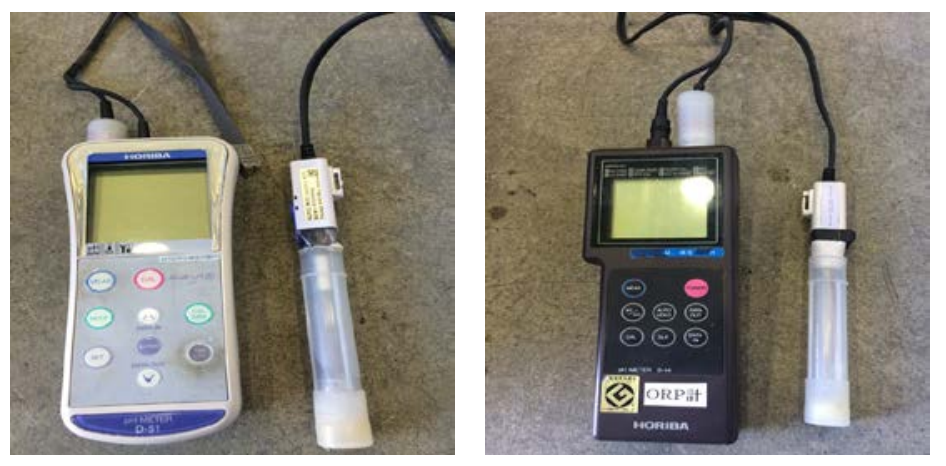

Figure 2. PH meter and ORP meter for water 
Table 1. Properties of different electrolyzed waters and admixtures

\begin{tabular}{|c|c|c|c|c|}
\hline Type & Code & Range of PH & $\begin{array}{c}\text { Measured PH } \\
\text { Value }\end{array}$ & $\begin{array}{c}\text { Measured ORP } \\
\text { Value }\end{array}$ \\
\hline Natural water & NW & 7 & 7.51 & 343 \\
\hline Cathode water 1 & CW1 & $9 \sim 10$ & 9.74 & 179 \\
\hline Cathode water 2 & CW2 & $11 \sim 12$ & 12.21 & 224 \\
\hline Anode water & AW & $7 \sim 8$ & 8.06 & 457 \\
\hline Alkaline ion water & IW & $8 \sim 9$ & 8.62 & 194 \\
\hline Water reducer & WRA & $8 \sim 9$ & 9.6 & 32 \\
\hline Air entraining & AE & $6.5 \sim 7.5$ & 7.77 & 204 \\
\hline
\end{tabular}

Storage of electrolyzed water. From figure 3, it can be seen that the PH value of electrolyzed water has a continuous declination under the condition of no cover with days, which would lead to the failure of electrolyzed water eventually; while unchanged basically with cover in tightly sealed container. Therefore, electrolyzed water should be long-term stored in a sealed container.

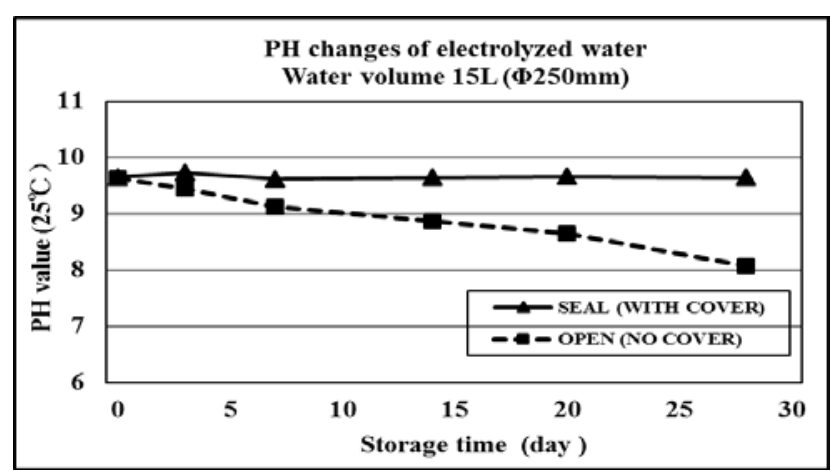

Figure 3. PH changes of electrolyzed water with days

Mixture proportions. Table 2 presents the detailed concrete mixture proportions used for this investigation. The water to cement ratio (W/B) of 0.5 was used to prepare concrete specimens throughout the experimental program. The sand coarse aggregate ratio (s/a) was $45 \%$. Because different types concrete should be compared and analyzed more reasonablly,the slump and air content of electrolyzed water concrete were controlled under the same condition by adding two kinds of admixture.(slump is $8.5 \pm 0.5 \mathrm{~cm}$, air content is $4 \pm 0.5 \%$.) The concrete specimens with $\Phi 100 \times 200 \mathrm{~mm}$ cylinders were prepared for test. The strength test of concrete was conducted at $14 \mathrm{~d}$, 28d and $91 \mathrm{~d}$ ages.

Table 2. Mixture Proportions of Electrolyzed Water Used for Concrete

\begin{tabular}{|c|c|c|c|c|c|}
\hline Mixture Designation & NW & CW1 & CW2 & AW & IW \\
\hline Water $\left(\mathrm{kg} / \mathrm{m}^{3}\right)$ & 167 & 166 & 166 & 167 & 166 \\
\hline Cement $\left(\mathrm{kg} / \mathrm{m}^{3}\right)$ & 344 & 344 & 344 & 344 & 344 \\
\hline Sand, Thick $\left(\mathrm{kg} / \mathrm{m}^{3}\right)$ & 722 & 722 & 722 & 722 & 722 \\
\hline Sand, Thin ${ }^{*}\left(\mathrm{~kg} / \mathrm{m}^{3}\right)$ & 80 & 80 & 80 & 80 & 80 \\
\hline Crushed Stone $\left(\mathrm{kg} / \mathrm{m}^{3}\right)$ & 968 & 968 & 968 & 968 & 968 \\
\hline Water-Reducing Admixture $\left(\mathrm{kg} / \mathrm{m}^{3}\right)$ & 4.1 & 4.1 & 4.1 & 4.1 & 4.1 \\
\hline Air Entraining Admixture $\left(\mathrm{kg} / \mathrm{m}^{3}\right)$ & 2.1 & 2.7 & 2.7 & 2.1 & 2.7 \\
\hline Slump $(\mathrm{cm})$ & 8.6 & 8.5 & 8.9 & 8.7 & 8.4 \\
\hline Air Content $(\%)$ & 4.5 & 4.8 & 4.3 & 4.7 & 5.2 \\
\hline Concrete Temperature $\left({ }^{\circ} \mathrm{C}\right)$ & 14.1 & 14.3 & 14.4 & 14.1 & 14.1 \\
\hline
\end{tabular}




\section{RESULTS AND DISCUSSIONS}

Compressive strength tests. The compressive strength tests for evaluating the compressive strength of the concrete mixtures were conducted according to JSCE-G 505. The specimens are made into $\Phi 100 \times 200 \mathrm{~mm}$ cylinders, three identical specimens were made for each specimen design. The test ages are $14,28 \mathrm{~d}$ and $91 \mathrm{~d}$, respectively.

Compressive strength development. The test results for compressive strength of the electrolyzed water concrete mixtures is shown in Figure 4. It can be seen that the strengths of all kinds of concrete increased with age.For the strength developement of concrete at the early age, the strengths of eletrolyzed water concrete all increased in comparison with the natural water concrete at $14 \mathrm{~d}$ and $28 \mathrm{~d}$.The strengths of two kinds of cathode water concrete were both higher than that of anode water concrete.It was obvious that compared with natural water concrete, the strength of CW1 concrete was highest, the strength of CW1 concrete increased by $22 \%$ at $14 \mathrm{~d}$ and $11 \%$ at $28 \mathrm{~d}$; the strength of AW concrete was lowest, the strength of AW increased by $8.1 \%$ at $14 \mathrm{~d}$ and only $4.3 \%$ at $28 \mathrm{~d}$. However, for strength developement of concrete at the long-term age, the variation trend of strength curve of concrete was different at 91d. Similarly, compared with natural water concrete,the strengths of cathode water concrete and alkaline ionized water concrete were both improved .The strength of CW1 concrete was still highest, increased by $12.6 \%$, , the strength of CW2 concrete increased by $6.8 \%$ and the strength of IW concrete increased by 9.7\%; on the contrary, the strength of anode water concrete unexpectedly decreased by $6.4 \%$. Therefore , a conclusion was drawn that the cathode electrolyzed water 1 was the optimum water used for concrete, and the slight alkaline of cathode electrolyzed water can contribute to improve the compressive strength of concrete.

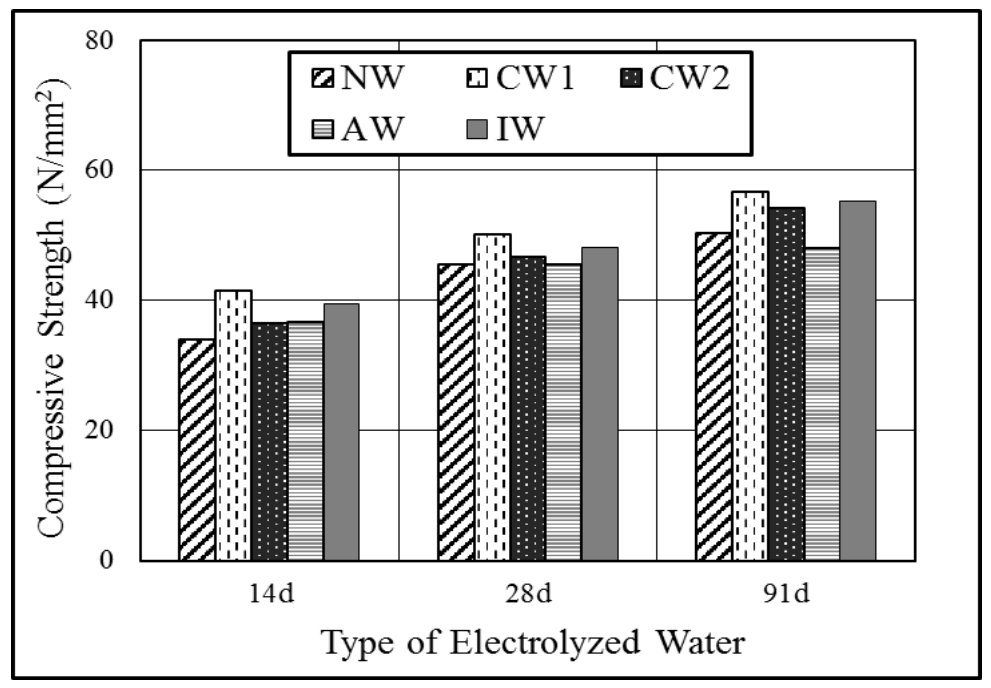

Figure 4. Compressive strength of electrolyzed water concrete

From what has been discussed above, it can be seen that using the cathode electrolyzed water can improve the strength of concrete effectively,while the anode water should not be used in concrete because of decreasement of strength. From the economic benefit, under the condition of same required strength,using cathode electrolyzed water in concrete would reduce the about $10 \%$ cement amount and associated $\mathrm{CO}_{2}$ emission. According to the report from Ministry of Economy, Trade and Industry in Japan this year, 62 million tons of cement was produced in 2015 in Japan. Based up on the results above, the electrolyzed water used in concrete may save the cement content of about $35 \mathrm{~kg}$ per cubic without 
strength loss for average cement content of $350 \mathrm{~kg}$ per cubic of concrete, This would save about 10,000 Japanese yens per cubic concrete, leading to reduce the cost for cement production and concrete construction. Because this study is still in the research and test stage, there is not yet a mass implementation of the results in concrete engineering, it needs a further research. The higher voltage, larger electrolyte concentration, lasting the electrolysis's time may benefit to a higher improvement of strength.

PH value's effect on strength of electrolyzed water concrete. The $\mathrm{pH}$ values of different types of electrolyzed water were different because of different types and concentrations of electrolyte in the process of electrolysis. Figure 5 illustrated the relationship between $\mathrm{PH}$ value of electrolyzed water and compressive strength of concrete. It can be seen that the strength curves of concrete showed a parabolic trend with the increase of $\mathrm{pH}$ value at different ages.

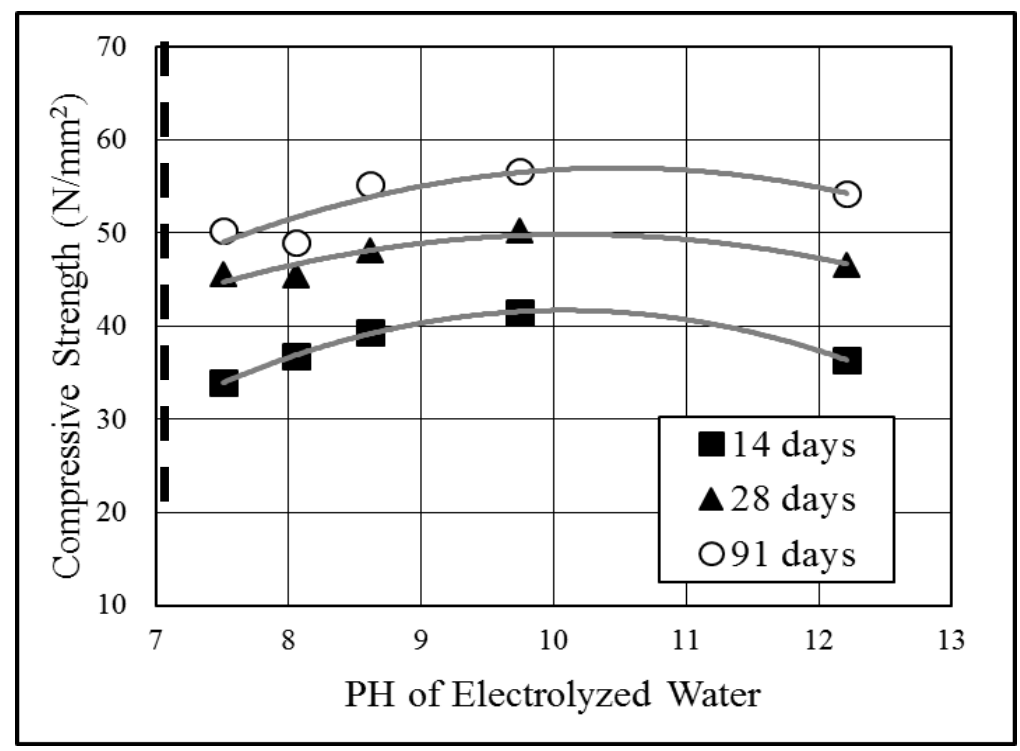

Figure 5. Relationship between compressive strength and PH

Because the relationship curves of strength were similar at different ages, the strength curve at 28 days was taken as an example here, the relation equation (1) of strength curve with $\mathrm{PH}$ was as follows:

$y=-1.1728 x^{2}+23.647 x+77.496$

Where:

$y=$ Compressive strength of concrete $\left[\mathrm{N} / \mathrm{mm}^{2}\right]$

$x \quad=P H$ value of electrolyzed water

According to equation (1), it can be calculated that the strength of electrolyzed water concrete would reach the maximum when $\mathrm{PH}$ value is about 10 .When $\mathrm{PH}$ value of water is below 10 , the strength of concrete increases with $\mathrm{PH}$ value ; however, when the $\mathrm{PH}$ value is higher than 10 , the strength of electrolyzed water concrete decreases slowly. In addition , if the $\mathrm{pH}$ value of water is higher than 10 , on the one hand ,the strong alkalies will be easy to cause a certain harm to the human body in experimental or construction; on the other hand, it has an apparent effect on the alkali - aggregate reaction and durability of concrete. Therefore, generally speaking, the $\mathrm{PH}$ value of electrolyzed water used for concrete should be controlled below 10 . 
ORP value's effect on strength of electrolyzed water concrete. ORP is short for Oxidation-Reduction Potential. ORP typifies the relative degree of oxidation or reduction of the medium (including soil, water, culture medium, etc.) as a comprehensive indicator. A positive ORP value means that the solution possesses the oxidability, the higher the ORP value, the oxidability of solution is stronger. A negative ORP value means the solution possesses excellent reducibility.

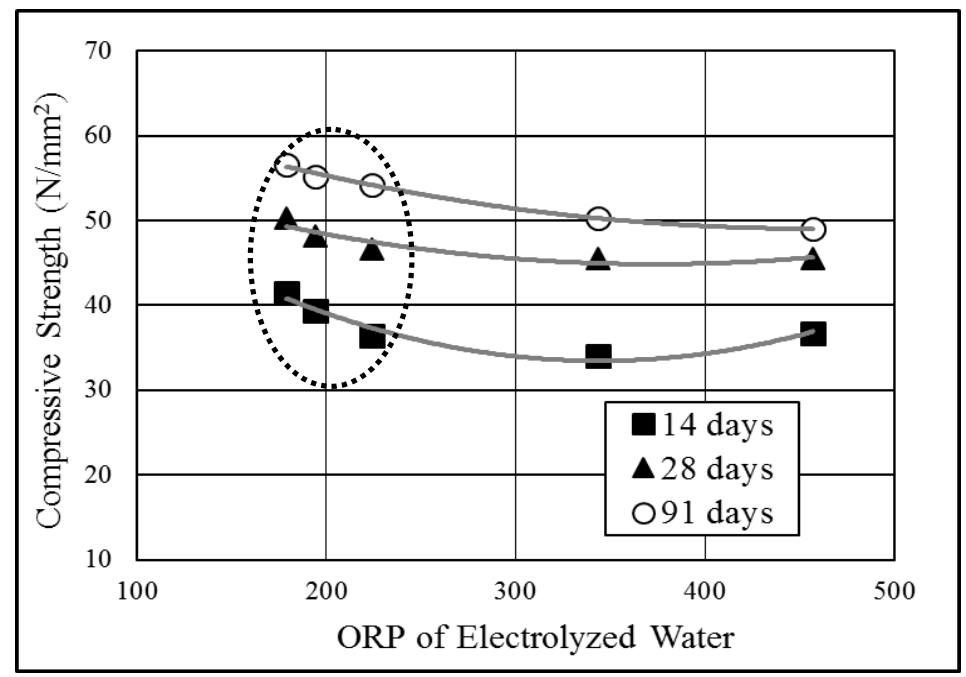

\section{Figure 6. Relationship between compressive strength and ORP}

Figure 6 shows the relationship between the ORP value of electrolyzed water and compressive strength of concrete. It can be seen that the oxidability of electrolyzed water is stronger as the ORP value increased, the strength of electrolyzed water concrete decreased overall at $28 \mathrm{~d}$ and $91 \mathrm{~d}$. The ORP value of electrolyzed water is mainly concentrated in the 200 or so, the strength of electrolyzed water concrete is relatively higher in this case; when the OPR value is higher than 300, the strength of concrete decreases obviously at 91days. Meanwhile, too strong oxidability of water has a great effect on the durability of concrete. Therefore, the ORP value of electrolyzed water used for concrete should be controlled around 200 during the process of preparation.

\section{Mortar mixtures using the electrolyzed water}

From the discussion above, the cathode electrolyzed water 1 (CW1) was the optimum water used for concrete. In order to find out the reason why the cathode electrolyzed water can improve the strength of concrete, the comparison tests of three groups of mortar were conducted. Differential thermal analysis (TG/DTA) was used to measure the $\mathrm{Ca}(\mathrm{OH})_{2}$ amount in mortars. The degree of hydration and reaction mechanism of electrolyzed water in mixture would be analyzed and determined. Regarding the mixture proportion, the volume ratio of paste and sand in mortar was determined as 1: 1 in order to emphasize the changes of paste. The water to cement ratio (W/C) of 0.5 was used to prepare the specimens throughout the experimental program. Taking into consideration that the chemical characteristics of admixtures may have a certain effect on the performance of electrolyzed water mortar, CWM1 was made as blank control group to be compared and analyzed, and without water-reducing and air entraining admixture. The mark 'NWM' refers to natural water mortar (the PH value is 7.37 and the ORP value is 334), and the mark 'CWM' refers to cathode eletrolyzed water mortar (the PH value is 9.82 and the ORP value is 202). The datailed mixture proportion of three kinds of mortar is shown in Table 3. 
Table 3.Mixture Proportions and Flow of Mortar Mixtures

\begin{tabular}{|c|c|c|c|}
\hline Mixture Designation & NWM & CWM & CWM1 \\
\hline Water $\left(\mathrm{kg} / \mathrm{m}^{3}\right)$ & 304 & 306 & 306 \\
\hline Cement $\left(\mathrm{kg} / \mathrm{m}^{3}\right)$ & 612 & 612 & 612 \\
\hline Standard Sand $\left(\mathrm{kg} / \mathrm{m}^{3}\right)$ & 1315 & 1315 & 1315 \\
\hline Water-Cementitious Ratio (\%) & 0.5 & 0.5 & 0.5 \\
\hline $\begin{array}{c}\text { Water-Reducing Admixture } \\
\left(\mathrm{kg} / \mathrm{m}^{3}\right)\end{array}$ & 1.53 & 0 & 0 \\
\hline $\begin{array}{c}\text { Air Entraining Admixture } \\
\left(\mathrm{kg} / \mathrm{m}^{3}\right)\end{array}$ & 3.06 & 3.06 & 0 \\
\hline Flow (mm) & 228 & 222 & 224 \\
\hline Air Content (\%) & 3.8 & 4.0 & 0.5 \\
\hline
\end{tabular}

Compressive strength of mortar. From Figure 7, it can be seen that no matter whether the AE admixture was used or not, the compressive strengths of cathode electrolyzed water motar were both higher than that of normal water mortar at each age. Meanwhile ,because of the air-entraining admixture, the strength of cathode electrolyzed water mortar without AE admixture was the highest among the three kinds of mortar, increased by about $21 \%$ than that of natural water mortar at $91 \mathrm{~d}$. It revealed that using the cathode electrolyzed water in mortar or concrete not only can improve the strength, but also can save the amount of admixture.

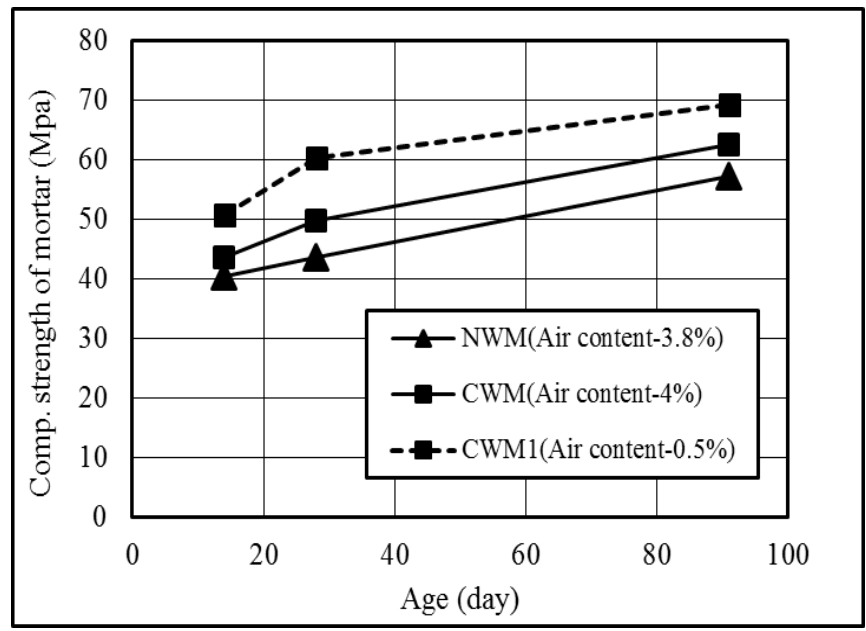

Figure 7. The change of $\mathrm{CH}$ amount of mortar with age

$\mathrm{Ca}(\mathrm{OH})_{2}$ amount in mortar with age. From Figure 8, it can be seen that the $\mathrm{CH}$ amounts of three kinds of mortar both increased with age, and it is obvious that under the same condition of additive of AE admixture, the $\mathrm{CH}$ amount of cathode electrolyzed water motar was obviously higher than that of normal water mortar at each age, the difference in values was narrowed at 91d. Therefore ,the reason may be that at the early age, there were many absorption positions with positive charge on the surface of cement particles (C3A, C3S.etc) [5], the highly active electrolyzed water with a strong negative charge could be fully absorbed and covered on the surface of cement particles, the double layer structure can make the particles evenly disperse because of electrostatic repulsion, the combined water in mortar was released and more, which would stimulate and promote the cement hydration and connection among particles, 
leading to the production of more C-S-H gels and $\mathrm{Ca}(\mathrm{OH})_{2}$ amount. The total porosity of mortar decreased and the strength increased. However, at the long-term age, the absorption positions on the surface of cement particles has reached the saturated condition, the difference in $\mathrm{Ca}(\mathrm{OH})_{2}$ amounts of different mortar became smaller.

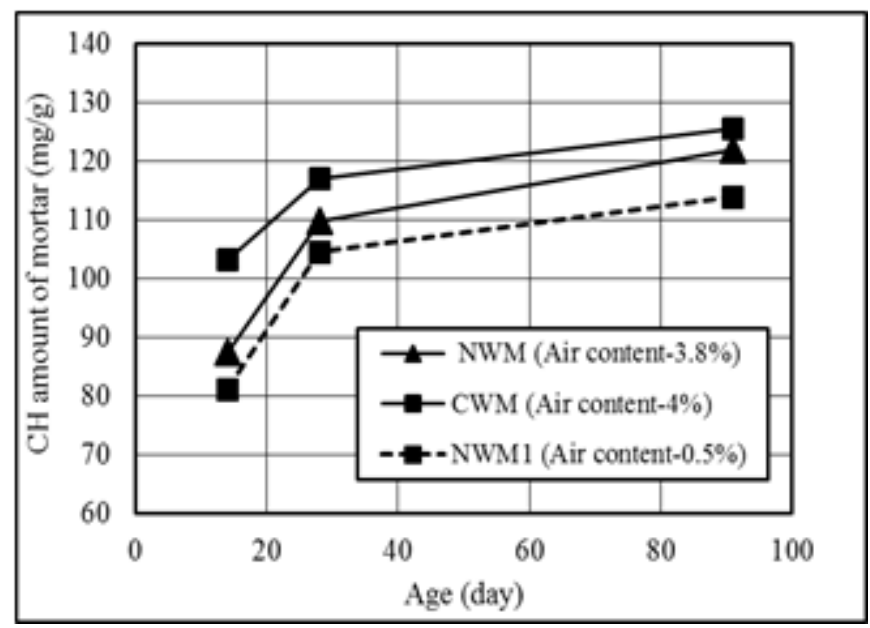

Figure 8. The change of $\mathrm{CH}$ amount of mortar with age

Figure 9 showed the relationship between $\mathrm{CH}$ amount and strength of mortar, the strength of mortar increased with $\mathrm{CH}$ amount in mortar. At the early age (14d and 28d), the higher hydration rate and more production of $\mathrm{CH}$ as well as $\mathrm{CSH}$ gel resulted in the greatly increase of strength of electrolyzed water mortar; However, at the long-term age (91d), the hydration reactions of two kinds of mortar were both relatively sufficient. The $\mathrm{CH}$ amount in natural water mortar at 91d was close to that of cathode electrolyzed water mortar, the difference of strength between electrolyzed water mortar and natural water mortar was narrowed, the strength of electrolyzed water mortar increased by only $6.8 \%$ than that of natural water mortar. The strength growth of mortar is much lower than that of concrete at $91 \mathrm{~d}$, this is because more CSH gels made the internal interface structure of concrete more complete and solid, the bond strength of interface was greatly improved.

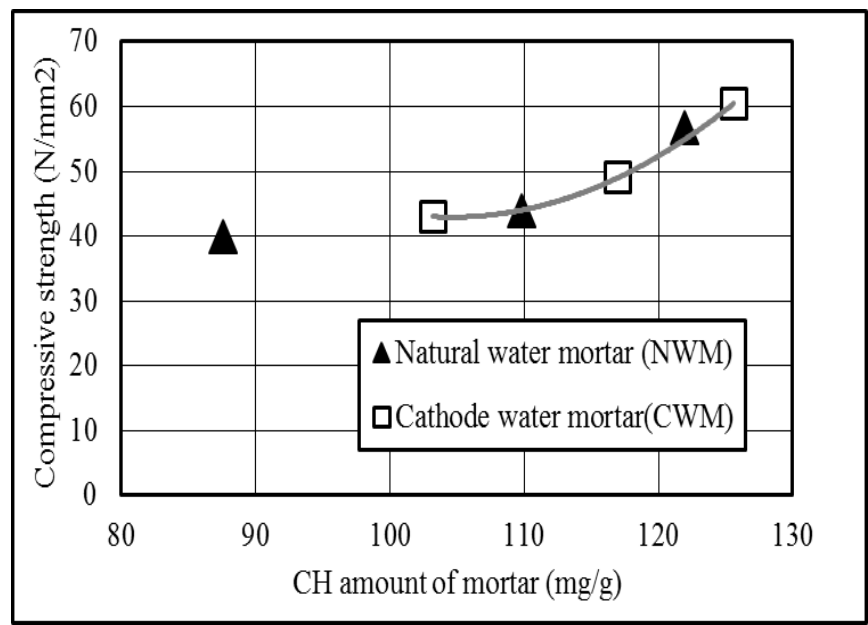

Figure 9. The relationship between $\mathrm{CH}$ amount and strength of mortar 


\section{CONCLUSION}

The following general conclusions can be drawn from the study provided in the paper:

- The strengths of concrete using the cathode electrolyzed water (CW1 and CW2) increased by $12.6 \%$ and $6.8 \%$ than that of natural water concrete at the long-term age,respectively. The strength of slightly alkaline ionized water concrete increased by $9.7 \%$ at $91 \mathrm{~d}$; while the anode water should not be used in concrete because of obvious decreasement of strength.

- The strong alkalies of electrolyzed water with overhigh PH will be easy to cause a certain damage to the human body and durabilities of concrete ,so the $\mathrm{PH}$ value of electrolyzed water should be controlled below 10. When the PH value of water is below 10, the strength of electrolyzed water concrete increased as $\mathrm{PH}$ value increased.

- The oxidability of electrolyzed water becomes stronger as the ORP value increases, the strength of electrolyzed water concrete decreased overall as ORP value increased .The ORP value of electrolyzed water should be controlled around 200 during the process of preparation.

- The CH amount of cathode electrolyzed water motar was higher than that of natural water mortar at each age, which reveals the free ions in electrolyzed water as catalyst could promote and stimulate the hydration reaction of cement in concrete to produce more C-S-H gels and $\mathrm{Ca}(\mathrm{OH})_{2}$, the interface structure between the coarse aggregate and the cement paste was more complete and solid, so the strength of concrete was improved effectively.

- Because this experiment is still in the research and test stage, there is not yet a mass implementation of the results in concrete engineering. The higher voltage, larger electrolyte concentration, lasting the electrolysis's time may benefit to a higher improvement of strength. From the economic benefit ,effective utilization of electrolyzed water in concrete probably would reduce the cement amount of concrete without strength loss and associated $\mathrm{CO}_{2}$ emission.

\section{ACKNOWLEDGEMENTS}

Support for this research project was provided by Tokyo Metropolitan University and AMANO Maintenance Engineering Co., Ltd.

\section{REFERENCES}

Ahmad R. M, Charles N. T. (2015). "Combined effects of slightly acidic electrolyzed water and fumaric acid on the reduction of foodborne pathogens and shelf life extension of fresh pork." Food Control, 47(1), 277-284.

Mahmoudreza, O, Hamzah M. Al-Qadiri (2015). "Efficacy of acidic and alkaline electrolyzed water for inactivating Escherichia coli O104:H4, Listeria monocytogenes, Campylobacter jejuni, Aeromonas hydrophila, and Vibrio parahaemolyticus in cell suspensions.” Food Control, 53(1), 117-123.

Sun. B.Q, Wang L.J. (2009). "Study on the Properties of Concrete Mixed with Alkaline Redox Potential Water.” Journal of Building Materials, 12(1).

Song. Z.J, Jiang L.H. (2011). "Review of researches on influence of solution composition on chloride diffusivity coefficient in concrete.” Advances in Science and Technology of Water Resources, 31(5).

T. Ding, X.T. Xuan, J. Li. (2016). "Disinfection efficacy and mechanism of slightly acidic electrolyzed water on Staphylococcus aureus in pure culture.” Food Control, 60(1), 505-510. 
T. Ding, Z.Ge, J. Shi. (2015). "Impact of slightly acidic electrolyzed water (SAEW) and ultrasound on microbial loads and quality of fresh fruits.” LWT - Food Science and Technology, 60(1), 1195-1199.

Tan. W, Li H.L. (2014). "The Effect of Electrolytes on Electrical Resistivity of the Ion Conductive Concrete.” Journal of Shihezi University (Natural Science), 32(4). 